\title{
Keratoconus keratoplasty curvatures and contact lens wear
}

\author{
M. RUBEN AND E. COLEBROOK \\ From Moorfields Eye Hospital, City Road, London
}

SUMMARY Fifty-three grafted keratoconus corneas chosen at random from several hundred operated upon over a 10-year period showed an increase in myopia after removal of sutures but a decrease in astigmatism. With the photoelectrokeratograph machine the spherical zone was shown to be limited to $3 \mathrm{~mm}$ with gross eccentricities. Half the patients chose to wear contact lenses after surgery and $10 \%$ had no correction. Contact lens wearers showed a much greater decrease in astigmatism than spectacle wearers.

The treatment of keratoconus by keratoplasty would be ideal if the curvatures of the donor graft resulted in an emmetropic eye. But for several reasons this is rarely possible. The chief reasons given are light transmission defects of the graft tissue or irregularities in curvature of the donor corneal surface. Analysis of curvatures even suggested to previous workers that keratoconus recurs in the grafted eye. It will not be the purpose of this paper to discuss light transmission problems, which are chiefly concerned with endothelial survival and function, or the several problems that result in opacities, either partial or total, of the graft. The latter are usually associated with either inflammatory reactions of healing or immunological reactions.

The various aspects of graft size, shape, and suturing techniques have been dealt with by several workers. The conclusions so far are that, while size and shape may alter the final curvature (Ruben, 1972; Troutman and Meltzer, 1972; Troutman, 1973), the reasons why they do so are not fully known. According to Ruben (1972) the relationship between average keratometry and size was related to graft size; thus the large grafts resulted in overall flatter curvatures. Recent work by Davies et al. (1976) disputes a statistical relationship between number of sutures but favours more the tension present in sutures. Indeed, it is well known that the tension, when released on removal of sutures even one-and-a-half years after grafting, results in sudden changes of graft curvatures. This has led some surgeons to leave graft sutures of 10-0 Perlon in

Address for reprints: Mr M. Ruben, FRCS. Moorfields Eye Hospital, City Road, London ECIV 2PD the eye indefinitely, provided vision is satisfactory and the astigmatism is low.

An alternative approach has been to mould the graft by means of a contact lens fitted some 6 to 12 weeks after surgery and with the Perlon sutures in situ, the contact lens usually being hard, but softer materials are often used.

This paper analyses the keratoplasty curvatures of 48 patients, of whom 5 had bilateral keratoplasty. The keratometry findings will be correlated with the age of the graft, and in those cases in which contact lenses have been worn the degree of initial astigmatism, with that after prolonged periods of wear, will be described. Mean average of graft keratometry and acuity will also be given. The value, therefore, of the contact lens as an adjunct to keratoplasty will be discussed from these results.

Further work on graft sensitivities and thickness has been done where possible in all these patients and will be reported in separate papers.

\section{Method}

The Contact Lens Department at Moorfields Eye Hospital has over a 10-year period done several hundred grafts routinely, chiefly of 7 or $8 \mathrm{~mm}$ diameter, by the conventional surgical technique of interrupted and more recently (over the past 6 years) of continuous-only suturing. Case reports have been taken from the files at random and the patients followed up as they attended the clinics, when they underwent careful testing of refraction, keratometry (including photoelectrokeratogram), and contact lens acuity. 


\section{Results}

\section{AGE OF GRAFT}

The shortest time from operation was 7 months and the longest time 120 months (10 years). The average for the group was $62 \cdot 16$ months ( 5 years).

The numbers in each graft age group were as follows: 0 to 12 months, $8 ; 1$ to 2 years, $7 ; 2$ to 3 years, $4 ; 3$ to 4 years, $5 ; 4$ to 5 years, $3 ; 5$ to 6 years, 5 ; 6 to 7 years, $8 ; 7$ to 8 years, $8 ; 8$ to 9 years, 3 ; 9 to 10 years, 1 ; over 10 years, 1 . Total, 53 grafted eyes.

Directly after sutures were removed (average, 6 months) the average spherical ametropia was $-1 \cdot 82$ dioptres and the average astigmatism 4.12 dioptres; axis oblique in $75 \%$; axis with the rule $15 \%$; axis against the rule $10 \%$. But at just over 5 years the refraction results were as follows: -3.64 for equivalent spherical ametropia, and average astigmatism 3.43 dioptres. The axes were oblique $74 \%$; with the rule $13 \%$; and against the rule $13 \%$. There were 3 eyes in the last group without measurable astigmatism (below 0.25 dioptres), whereas all eyes before the sutures were removed had measurable astigmatism.

In 6 instances the astigmatism changed its axis more than $45^{\circ}$. Two cases showed a $90^{\circ}$ change of axis; they were both contact lens wearers and the grafts were more than 3 years old. Where measurable, the corrected spectacle acuity immediately after sutures were removed averaged 6/12. But 11 patients had no measurable spectacle acuity at this time, possibly owing to graft irregularity and/or oedema. The final average acuity with spectacles was $6 / 13 \cdot 7$. The change of acuity could be analysed further in each graft age group, but the small numbers involved would not yield a statistically significant result. It was found that $67.5 \%$ had $6 / 9$ or better acuity immediately after taking out the sutures, and at the 5-year average age period this figure had dropped to $58.7 \%$

The results are shown in Table 1.

Table 1 Distribution of astigmatism after removal of sutures

\begin{tabular}{lll}
\hline & $\begin{array}{l}\text { After removal } \\
\text { of sutures }\end{array}$ & $\begin{array}{l}\text { 4 years average } \\
\text { age of graft }\end{array}$ \\
\hline $\begin{array}{l}\text { Average spherical equivalent } \\
\text { ametropia }\end{array}$ & $-1 \cdot 82$ & -3.64 \\
Astigmatism in dioptres & $4 \cdot 12$ & 3.33 \\
Axis of astigmatism, oblique & $75 \%$ & $74 \%$ \\
& $15 \%$ & $13 \%$ \\
Acuity (average) & $10 \%$ & $13 \%$ \\
\hline
\end{tabular}

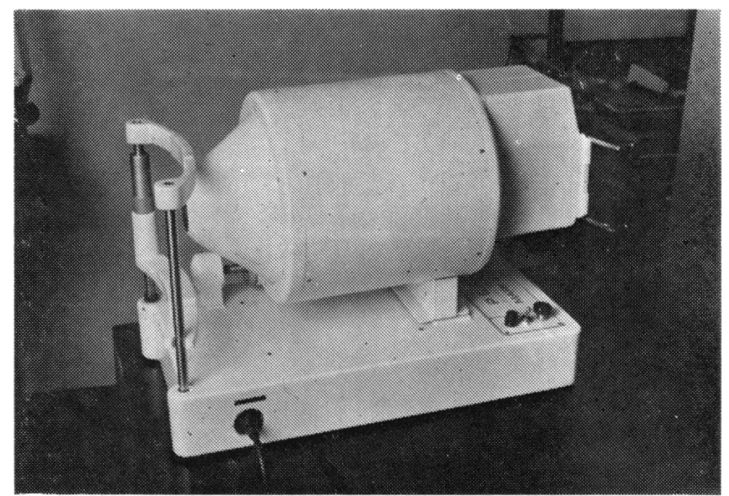

Fig. 1 PEK Wesley-Jessen machine for topographical keratometry

The highest degree of astigmatism measured was 13 dioptres in an eye immediately after removal of sutures.

A topographical photoelectrokeratograph (PEK) was done on the Wesley-Jessen machine (Fig. 1) in 20 patients and analysed to give eccentricity readings. The eyes were measured at the average time of 5 years.

Keratography shows alterations in the surface of the cornea by means of a photograph of the reflected image of a target. The target in the case of the photoelectric keratoscope is a series of illuminated concentric circles with the inner circles furthest away from the eye being photographed and the largest circle nearest. They are arranged in this manner so that their image in the cornea is flat. The camera is fixed so that its lens is concentric with the target.

To take a keratograph the patient's head is positioned in the headrest so that the eye to be photographed is aligned with the central target aperture. The patient focuses on the centre of the illuminated crosswire, which marks the centre. The operator views the reflected image through the eyepiece, which has a split screen to aid focusing. When the rings are continuous and in sharp focus the photograph is taken.

The keratograph must have at least three central rings in sharp focus in one meridian before the computer can evaluate the shape factor and eccentricity of the cornea photographed.

PEK ANALYSIS

The individual curves taken from PEK of grafted eyes selected at random have had their variances from the normal magnified $\times 1000$ to show how graft curves differ quantitatively and qualitatively (Figs. 2 to 5). It must be pointed out that these individuals (denoted by numbers) have clear success- 
Superior

Right Eye Vertical

EYE DRAWN X10 LIFE-SIZE
( NORMAL EYE RADIUS TAKEN AS $7.80 \mathrm{~mm}$.)
VAR IATION OF GRAFTED CORNEAS
X1000 LIFE-SIZE IN $\longleftrightarrow$ DIRECTION

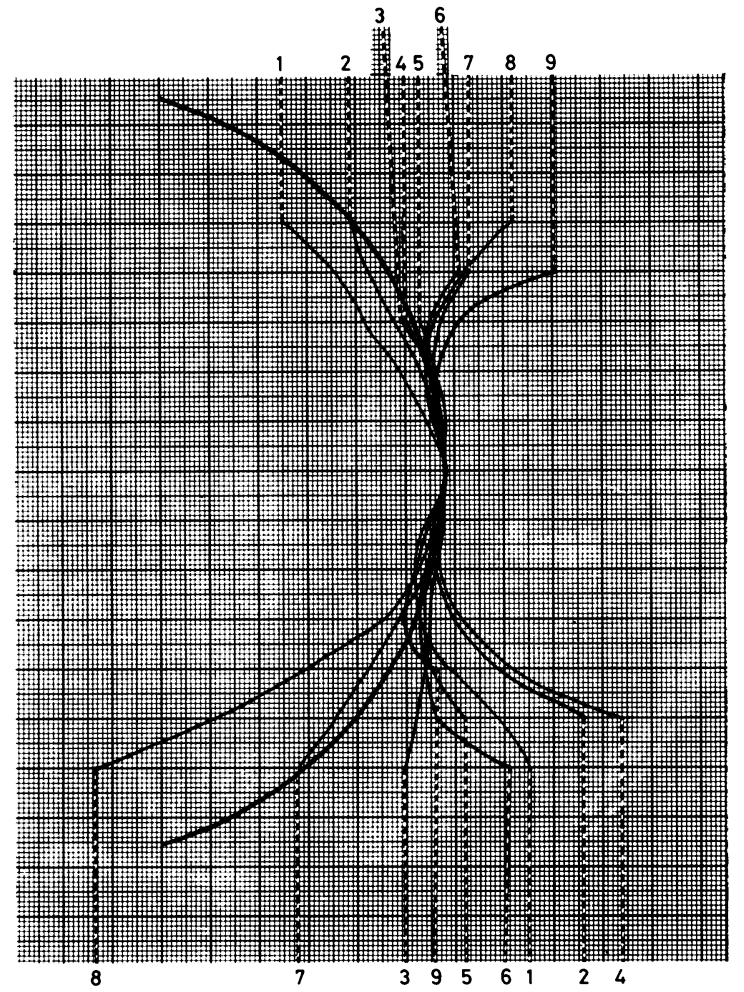

Inferior

Fig. 2 Vertical section, right eye, of 9 graft curvatures. Continuous black line $=$ normal cornea $; \mathrm{r}=7 \cdot 8$. $P E K$ data $\times 1008$ co-ordinate

ful grafts and were corrected with contact lenses to the good acuities previously described.

The PEK measures the topographical keratometry in 2 meridians at $90^{\circ}$ to each other over $10-\mathrm{mm}$ chords. The diagram shows that the variance from normal corneal curve of $r=7 \cdot 80$ over the central 1 -mm chord is $\pm 0.003 \mathrm{~mm}$ (measured in the line of the central axis); that at the limits of the 4-mm central chord the variance is $\pm 0.009 \mathrm{~mm}$; and that at $6 \mathrm{~mm}$, which must be considered the limits of good optical quality of most grafts, the variance from normal is in the region of $\pm 0.015 \mathrm{~mm}$.
The graft outlines shown in this way give an impression that the majority of curves are within normal sphericity over a 3- to 4-mm chord, but then deviate. There are too few curves from which to draw statistically significant conclusions. But any corneal curve which progressively changes so that a difference of 1 dioptre occurs within a chord increase of $2 \mathrm{~mm}$ can be said to be clinically eccentric. With the above method of monitoring curves this is equivalent to a $0 \cdot 10-\mathrm{mm}$ deviation or \pm 0.05 - $\mathrm{mm}$ variance. We see, therefore, on applying

Superior

Left eye Vertical

EYE DRAWN X10 LIFE-SIZE

( NORMAL EYE RAD IUS TAKEN AS $7.80 \mathrm{~mm}$.)

VARIATION OF GRAFTED CORNEAS

$X 1000$ LIFE-SIZE IN $\leftrightarrow$ DIRECTION

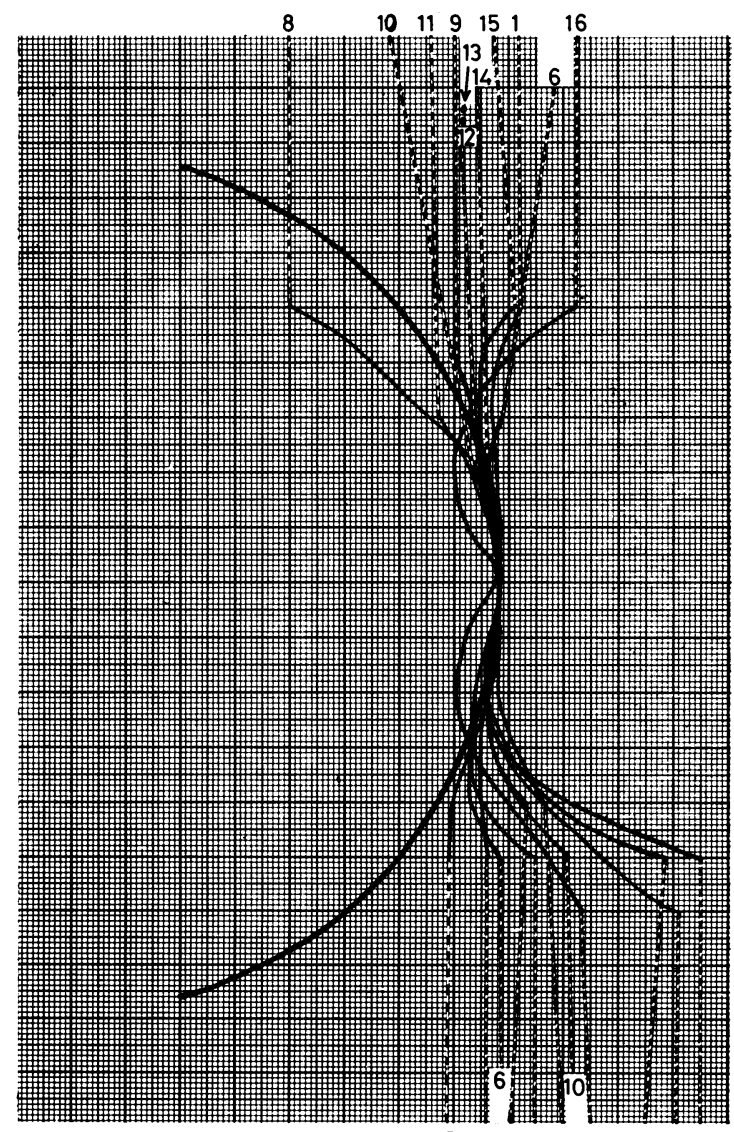

Inferior

$\begin{array}{lllllll}15 & 14 & 9 & 13 & 16 & 11 & 812\end{array}$

Fig. 3 Vertical section, left eye, graft curvatures 
Fig. 4 Horizontal section, right

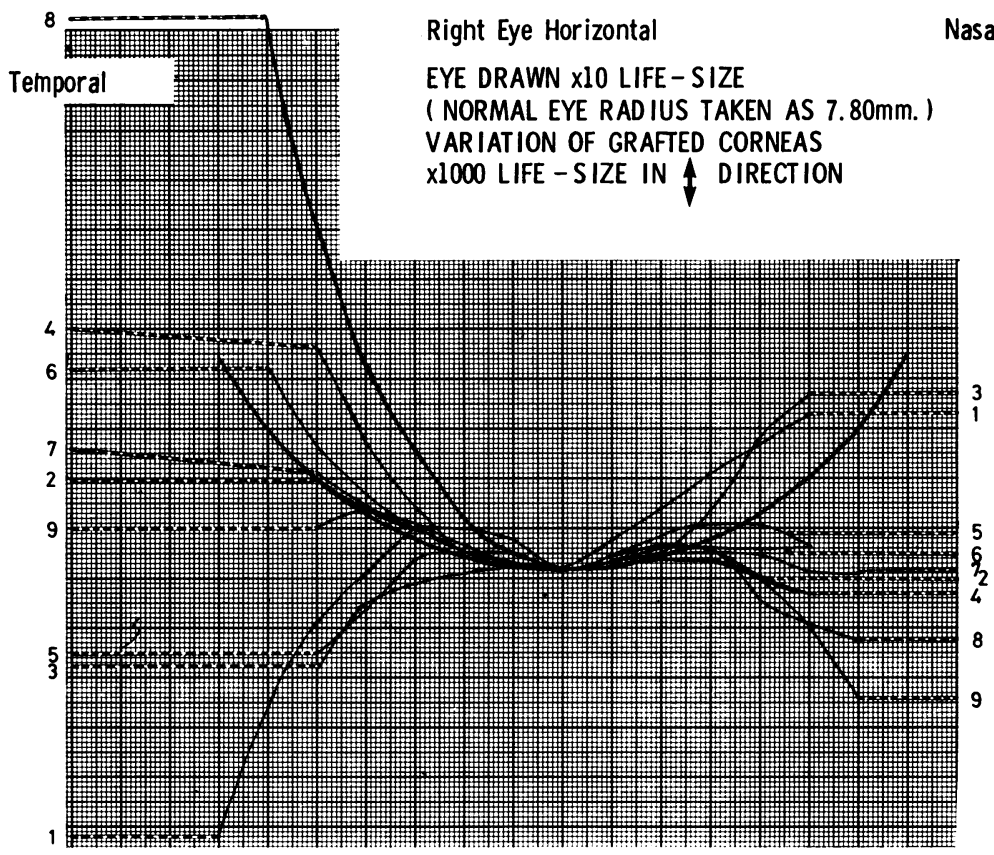
eye, graft curvatures

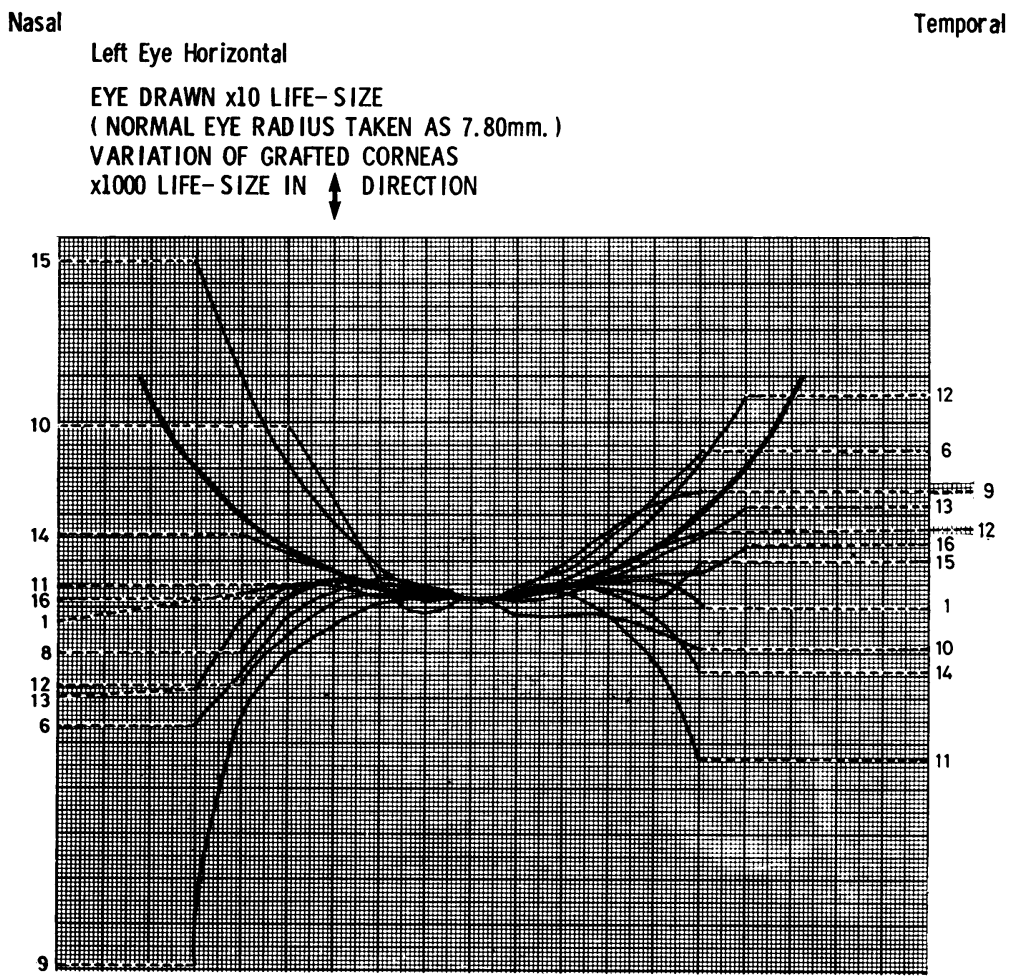

Fig. 5 Horizontal section, left eye, graft curvatures 
this rough guide of clinically significant eccentricity, that with the exception of patients $\mathrm{CN}$ and GN, all eyes are better than this. However, the distribution of eccentricity is not regular in any meridian measured.

To correlate eccentricity of graft curvatures with acuity is difficult. It best relates to corrected spectacle acuity, and those patients obtaining $6 / 6$ or better are $34.8 \%$ of the whole group. For such good acuities not only must the deviations from the normal be low but they must be the same in opposite meridians. For example, CJD (Figs. 2-5) is an extreme example of how the temporal and nasal deviations differ in the horizontal and in the vertical. Such eccentricities must be regularly placed about the centre in all quadrants to produce good acuity. Most of the curves illustrate this type of irregularity.

\section{KERATOMETRY}

The average keratometry after removal of sutures was 7.63 , the average flattest readings being 8.09 , and the steepest $7 \cdot 18$. The average astigmatism was $0.91 \mathrm{~mm}$ radius of curvature $(5.0$ dioptres); the steepest readings being 5.70 and the flattest 10.38 (not in the same cornea).

The readings taken at average age of graft 5 years after operation were respectively $7 \cdot 42$ (average), 7.75 (flattest), 7.11 (steepest), and astigmatism $0.4 \mathrm{~mm}(3.50 \mathrm{D})$, the steepest readings taken being 5.70 and the flattest 9.00 (see Table 2). There is therefore a significant change in $\mathrm{K}$ readings as the graft ages.

\section{ANALYSIS OF ASTIGMATISM IN GRAFT AGE} GROUPS

This was done to establish a trend, and the results are as follows. Table 3 shows that the 7-to 8-year-old grafts had a higher average astigmatism than the remainder. But since this result was due entirely to 3 high results (over 7 dioptres) out of a total of 7 cases it may have less significance.

No complete trend over the whole range could

Table 2 Distribution of keratometry readings after removal of sutures

\begin{tabular}{lll}
\hline & $\begin{array}{l}\text { After removal } \\
\text { of sutures }\end{array}$ & $\begin{array}{l}\text { At age of graft } \\
5 \text { years }\end{array}$ \\
\hline Average K & 7.63 & 7.42 \\
Average steepest K & $7 \cdot 18$ & 7.11 \\
Average flattest K & 8.09 & 7.75 \\
Mean astigmatism & $\begin{array}{c}0.91 \mathrm{~mm} \text { radius } \\
(4.60 \mathrm{D})\end{array}$ & $\begin{array}{c}0.64 \mathrm{~mm} \text { radius } \\
(3.20 \mathrm{D})\end{array}$ \\
\hline
\end{tabular}

Table 3 Graft age and astigmatism

\begin{tabular}{ll}
\hline Years & $\begin{array}{l}\text { Average } \\
\text { astigmatism in } D\end{array}$ \\
\hline $0-12$ months & $2 \cdot 84$ \\
1-2 years & $3 \cdot 00$ \\
2-3 years & $3 \cdot 19$ \\
3-4 years & $2 \cdot 30$ \\
4-5 years & $2 \cdot 00$ \\
5-6 years & $1 \cdot 70$ \\
6-7 years & 3.40 \\
7-8 years & $4 \cdot 60$ \\
8+ years & $2 \cdot 80$ \\
\hline
\end{tabular}

be seen, and high astigmatism after removal of sutures. But analysis of grafts where astigmatism was 4 dioptres or more after removal of sutures showed the following changes: 18 eyes with $4 \mathrm{D}$ or more astigmatism had an average keratometry of 6.84 after sutures were removed. After 1 or more years the average was reduced to $3.58 \mathrm{D}$. There is a marked trend for the higher degrees of astigmatism to reduce, which is not shown so clearly with overall averages. However, comparison of similar groups does show the trend for grafts to decrease astigmatism as the graft ages.

SPECTACLES AND CONTACT LENSES $50 \%$ wore contact lenses; $40 \%$ wore spectacles; $10 \%$ needed no correction. The wearing of a spectacle lens was not necessarily associated with the degree of astigmatism or acuity but more often with contact lens tolerance, acuity, and the state of binocular vision.

It is axiomatic that patients with lower degrees of astigmatism and myopia would be able to wear spectacles. Therefore the average change in astigmatism in patients wearing contact lenses was compared with the group not wearing contact lenses. In those wearing contact lenses astigmatism reduction averaged 3.125 dioptres; in those not wearing contact lenses astigmatism reduction averaged $0 \cdot 10$ dioptres.

\section{Conclusions}

Less than $4 \%$ of the group were highly myopic ( 2 patients), and in both instances steep keratometry was not the reason. The average keratometry of the grafts was steeper than normal corneal curvature (7.8) after the sutures were removed by almost $0.2 \mathrm{~mm}$, but after several months the tendency was 
towards a steeper curve to give the final average of $7 \cdot 42$, which cannot be considered keratoconic. There was a trend from an average astigmatism of just over 4 to a final 3.33. This almost agrees with the average keratometry recorded (see Table 1), and therefore the astigmatism measured by refraction agrees with the corneal curvatures. The axis of astigmatism was in most cases oblique, and remained so even several years after the operation. But extreme degrees of astigmatism showed a greater change towards normality than to be expected; moreover, in a few instances a complete change in axis was seen. Also of interest was the equal distribution of against and with the rule astigmatism. This all suggests that suturing has a great influence on maintaining curvatures of the graft, and that, once removed, corneas under severe stress gradually assume a trend towards the normal corneal curvatures.

Since almost an equal number of patients with grafts wore contact lenses for correction as wore spectacles, the most significant factor to emerge from the results was the marked decrease in astig- matism in the group wearing contact lenses as compared with those who did not. It is our practice to allow hard corneal lens or scleral lens wearers to obtain good acuity before the sutures are removed in some instances and, therefore, the lenses may be said to have a moulding effect on the graft which is beneficial.

We thank Wesley-Jessen, of Chicago, USA, for the loan of the PEK machine.

\section{References}

Davies, P. D. Ruben, M., and Woodward, E. G. (1977). Keratoconus: an analysis of the factors which influence the optical results of keratoplasty. Paper read at European Contact Lens Society of Ophthalmologists Symposium, Ghent, March 1977 (in press).

Ruben, M. (1972). Contact lens and keratoplasty curvatures. In Corneal Grafting, pp. 244-280. Edited by T. A. Casey. Butterworth: London.

Troutman, R. C., and Meltzer, M. (1972). Astigmatism and myopia in keratoconus. Transactions of the American Ophthalmological Society, 70, 265-272.

Troutman, R. C. (1973). Astigmatism and myopia in keratoplasty. South African Archives of Ophthalmology, 1, 29-35. 